This item is the archived peer-reviewed author-version of:

Effective field trips in nature : the interplay between novelty and learning

\title{
Reference:
}

Boeve-de Pauw Jelle, Van Hoof Jan, Van Petegem Peter.- Effective field trips in nature : the interplay betw een novelty and learning Journal of biological education - ISSN 0021-9266 - 53:1(2019), p. 21-33

Full text (Publisher's DOl): https://doi.org/10.1080/00219266.2017.1418760

To cite this reference: https://hdl.handle.net/10067/1481040151162165141 


\section{Effective field trips in nature: The interplay between novelty and learning}

Jelle Boeve-de Pauw, Jan Van Hoof \& Peter Van Petegem

Research Unit Edubron, dept. of Training and Education Science, Faculty of Social

Sciences, University of Antwerp. Prinsstraat 13, 2000 Antwerp, Belgium.

jelle.boevedepauw@uantwerp.be

Version as accepted by Journal of Biological Education

\section{Abstract}

Educational field trips are common practice in environmental education and education for sustainable development, well recognised by researchers for their potential to achieve cognitive and affective educational outcomes. One of the factors that influences learning during field trips is their novelty. The current study focuses on the interplay between novelty, preparation and environmental learning outcomes of $5^{\text {th }}$ and $6^{\text {th }}$ grade students during a typical field trip in Flanders. Our dependent variables are Inclusion of Nature in the Self, the two major ecological values Preservation and Utilisation and ecosystem knowledge. The sample includes 484 students (10-12 years old) and their 24 teachers. Key questions addressed are: (1) What is learned during the field trip? (2) What is the level of novelty for students during a field trip? (3) How does the novelty effect relate to learning? Results show that participation in the field trip leads to a substantial increase in ecosystem knowledge, but fails in reaching the affective goals set out by the field trip organizers. Our results furthermore provide support for the hypothesized non-linear relationship between novelty and knowledge gain, showing that while a little novelty is positive, too much novelty can stand in the way of learning.

Keywords: field trips; novelty effect; preparation 


\section{Introduction}

Go my children, burn your books. Buy yourselves stout shoes; get away to the mountains, the deserts, and the deepest recesses of the earth. Mark well the distinction between animals, the differences among plants, the various kinds of minerals. In this way, and no other, will one gain true knowledge of things, and of their properties (Severinus, 1571).

\section{The context of Flanders}

In tackling the environmental crisis, environmental education (EE) and education for sustainable development (ESD) are recognised to be important tools to address knowledge, values and behaviour in achieving sustainable development (e.g. United Nations, 2005).

Just as they do elsewhere, schools in Flanders play an important role. In the Flemish education system, EE and ESD are not a part of the science curriculum, but of a range of crosscurriculum goals, both cognitive and affective. Flemish schools have to prove (to the inspectorate) that they make an effort and that they try to achieve these goals (Sleurs et al., 2008) and they do so in different ways. While a high proportion of schools engage in the ecoschool program (Boeve-de Pauw \& Van Petegem, 2011) or similar certification programs, another common practice is to engage in out-of-school activities. In this case, teachers swap their classroom as the learning environment for a day trip to a destination such as a (local) nature reserve. Nature centres provide, among other things, excursions tailored to the crosscurricular goals of formal education in Flanders; they aim to work on cognitive as well as affective outcomes. Typically, students in primary education (ages 6-12) will visit natural areas in the proximity of their school several times during their primary education. During these excursions, it is common for a nature guide or educator to support or replace the teacher.

Educational field trips are a common practice used in EE and ESD (e.g. Meiers, 2010). They are recognised by researchers to be an educational approach with high potential to complement and enhance classroom teaching in informal settings and to achieve a wide range of educational goals (e.g. Orion \& Hofstein, 1994). Teachers and informal educators tend to agree on the educational value of field trips. A wide range of research outlines the positive cognitive and affective effects of field trips (e.g. Dewitt \& Storksdieck, 2008; Dillon et al., 2005), suggesting they provide opportunities to learn in ways that add value to classroom experiences (e.g. Rickinson et al., 2004). However, school field trip practice is currently under pressure and there has been a general increase in accountability (e.g. Dewitt \& Storksdieck, 
2008). In Flanders, this trend is reinforced by legislation that limits the school fees parents can be charged.

\section{Theoretical framework}

\section{Affective outcomes of field trips}

One aim of EE/ESD is to empower students to make informed decisions about their own environmental or sustainability behaviour. Knowledge is often seen as a precondition for sustainable behaviour. Classical models of environmental education assume a linear relationship between knowledge and behaviour (Kollmuss \& Agyeman, 2002). Such models have been proven to be too simplistic, yet they are still generally regarded by current professional practice (Kollmuss \& Agyeman, 2002). Contemporary models reduce the role of environmental knowledge and put a greater emphasis on environmental values as a key to environmentally responsible behaviour (Roczen et al., 2014). The importance of knowledge should not be underestimated, but it is best considered as interconnected with other precedents of behaviour, such as values and emotions (Roczen et al., 2014). In their much used Two Major Environmental Values framework (2MEV), Wiseman and Bogner (2003) state that "environmental values are determined by one's position on two orthogonal dimensions: a biocentric dimension that reflects conservation and the protection of the environment (Preservation or $\mathrm{P}$ ) and an anthropocentric dimension that reflects the utilisation of natural resources (Utilisation or $U)^{\prime \prime}$ (р. 5). This framework has been confirmed by scholars across several countries and regions, including Flanders (Boeve-de Pauw \& Van Petegem, 2011), and is in line with the current interpretation of sustainable development (SD) in Flanders (Van Poeck \& Loones, 2010), which proposes that preserving and utilising natural resources should be balanced, rather than seen to be competing, in order to achieve SD. If we have in mind that one of the main goals of environmental education initiatives such as the one we are investigating in the current study is to contribute to the pro-environmental behaviour of participants, than it is important to address soms results that connect the $2 \mathrm{MEV}$ to such behaviour. Across different studies there seems to be a consensus on the differential contribution of the $\mathrm{P}$ and $\mathrm{U}$ dimension to the facilitation of environmental behaviour. Milfont \& Duckitt (2004) showed that while increased preservation values do positively enhance the prevalence of environmental behaviors, decreased utilization values do not. In this sense, if we consider $\mathrm{P}$ and $\mathrm{U}$ as possible outcomes of EE interventions, then increased preservation values would have to be prioritized over decreased utilization values. Research by Milfont, Duckitt \& Cameron (2006), and Boeve-de Pauw \& Van Petegem (2013) shows that such patterns can 
depend on cultural contexts, and has at the same time confirm the differential impact of $\mathrm{P}$ and $\mathrm{U}$ on environmental behaviour within the cultural context of Flanders.

As well as knowledge and values, recent research includes another factor influencing environmental behaviour: an affective connection to the natural environment. Wilson (1992) introduces this notion in his popular work on biophilia, in which he hypothesises about an instinctive bond between human beings and other living things. Schultz $(2002$, p. 67) defines the concept as "the extent to which an individual includes nature within his/her cognitive representation of self". Roczen et al. (2014) integrate an affective connection to nature into their competence-model for environmental education, and according to Liefländer et al. (2013), "improving connectedness to nature should be a high priority in all environmental education where the goal is providing the knowledge needed to achieve a sustainable society" (p. 380). Recent research by Otto and Pensini (2017) shows that, in the context of naturebased environmental education, connectedness to nature much strong relates to environmental behaviour than environmental knowledge. In summary, the research supports the idea that development of environmental knowledge, inclusion of nature in the self and environmental values are three key goals for contemporary EE and ESD. Rather than aiming for overt behaviour change (through a behaviouristic lens), it is valuable to reinforce these three factors because they are considered important precedents of behavioural change.

\section{Effective field trips}

\section{Field trips as a learning environment}

Field trips are common practice in formal education (e.g. Meiers, 2010). In Flanders, every year thousands of students and teachers swap their classrooms for what Donaldson and Donaldson define as "education in, about and for the outdoors" (as cited in Morag \& Tal, 2011). Researchers stress the informal character of such excursions, which have characteristics of both formal and informal learning (Hofstein \& Rosenfeld, 1996). Learning in field trips and learning in the classroom are connected in a relation described by Orion (1993) as a cyclic process of alternating concretisation and abstraction. Field trips offer learners opportunities to develop their knowledge and skills in ways that add value to their classroom experiences (e.g. Dillon et al., 2006).

The positive effects of excursions are repeatedly described by researchers (e.g. Bitgood, 1989; Dewitt \& Storksdieck, 2008; Behrendt \& Franklin, 2014). Not only are cognitive learning effects realised; field trips are a useful was of achieving a wide range of affective goals, and even short EE activities can have an impact (e.g. Bogner, 1998; Sellman \& Bogner, 
2013; DeWitt \& Storksdieck, 2008). Most teachers agree on this point and support the educational value of field trips.

\section{Field trip preparation}

Field trips should not be stand-alone experiences (e.g. Kisiel, 2006). Various theoretical models include a pre-trip phase, in which participants should be prepared for the field trip (Morag \& Tal, 2011). Bitgood (1989) distinguishes the pre-trip phase as the first of three phases, the Integrated Experience Model of Storksdieck (2006) outlines eight pre-trip-variables and the Fieldtrips in Natural Environments (FiNE) model contains four circles, of which planning and preparation is the first (Morag \& Tal, 2011).

The role of the teacher is key in extending school trips' impact via preparation and follow-up activities (DeWitt \& Storksdieck, 2008). Although a number of teachers are convinced of the importance of such field trip preparation, research indicates that many give their students limited, if any, preparation (Kisiel, 2005). Griffin and Symington (1997) find in one case that $50 \%$ of teachers can't formulate the goals of an excursion. There appears to be a gap between teachers' perceptions about field trips and their actual behaviour. One possible reason for this gap is a shortage of time or suitable material (e.g. Anderson \& Zhang, 2003; DeWitt \& Osborne, 2007; DeWitt \& Storksdieck, 2008). Michie (1998) identifies seven barriers to successful field trips, one of which is the teacher's ability to prepare. Tal and Morag (2009) describe challenges teachers face in this regard, such as lack of confidence, issues with class management and inadequate student motivation. They suggest there is a need to encourage teachers to carry out outdoor learning activities. Careful preparation yields a positive outdoor teaching experience, while a lack of preparation can prevent students from learning during a field trip. One reason for this is the "novelty effect".

\section{The novelty effect}

The "novelty effect" was introduced by John Falk and colleagues (e.g. Falk, 1983). Novelty in this regard can be defined as the extent to which students feel familiar with the field trip's content, its methods and its physical environment (e.g. Balling \& Falk, 1980; Falk, 1983). The novelty of a setting can create both curiosity and anxiety and thus facilitate or impede learning (Falk, 1978). Orion and Hofstein (1994) identify three dimensions of novelty - cognitive, geographic and psychological - which together define the "novelty space" of a learning environment. In recent studies, "social novelty" is sometimes added as an additional 
component of the "novelty space" (Elkins \& Elkins, 2007; Cotton, 2009).

Compared to a classroom, well known to the students, novelty of an informal learning environment is usually high (Anderson \& Lucas, 1997). Optimising novelty has therefore been suggested to be an important factor in improving learning outcomes. Student preparation can help achieve this optimal level of novelty (Griffin \& Symington, 1997). The effect of novelty on learning ability is not linear (Falk, 1983). Optimal learning seems to occur in settings of moderate novelty, while too little novelty in a learning environment can cause boredom and too much can be distracting or create anxiety. Note that the novelty of a field trip setting is not the same for all participants. The novelty that is experienced is the result of several factors, including earlier experiences (e.g. visits with family) and preparation provided in the classroom by the teacher.

\section{Current study}

In the current study, we focus on the impact of a nature excursion on ecosystem knowledge, environmental values (preservation and utilisation) and the experienced affective connection to nature by Flemish $5^{\text {th }}$ and $6^{\text {th }}$ graders. We also focus on how teachers in Flanders prepare their students for an excursion, and how this has an impact on the effectiveness of the excursion.

The field trip under study is one to the Kesselse Heide, a 43 ha heathland area near Flanders' largest city, Antwerp. The regional government - the province of Antwerp - is the owner of the area, responsible for organising a range of educational activities. Among these activities are autumn excursions for students in primary education, organised in September and October. Annually, about 500 students aged 10-12 participate in these guided walks, typically in class groups of about 20 students.

The pedagogy and approach of these field trips are highly standardised; the trips have a fixed content, route and activities. Small variations in content and pedagogy occur depending on the guide and field trip conditions (e.g. weather). Typically, students receive a two-hour tour through the heathland area, in which they experience alternating moments of explanation by the nature guide, and teaching conversations, playful moments and simple activities of investigation and exploration. To perform these activities, the guide carries a series of educational materials in a wagon. Like many other service providers, the province of Antwerp relies on a combination of a volunteer corps and paid staff to facilitate school tours. The trip is mainly guide-centred with the teacher playing a generally passive role. The field trip objectives include cognitive as well as affective goals (Provincie Antwerpen, n.d.). Cognitive goals pursued 
by the organiser are mainly in ecosystem knowledge. There is little attention to acquisition of other forms of knowledge.

Two points must be noted here. First, however important, the field trip pedagogy is not subject of this research. The focus of this work is on the impact of what took place before the trip. Second, the field trip has not been chosen because it's a particularly good example of EE/ESD practice, but because it exemplifies educational school trip practice in Flanders. Consequently, this trip is a subject with high relevance in exploring the impact of novelty. The field trip objectives include cognitive as well as affective goals (Provincie Antwerpen, n.d.). As is common practice, only intuitive and partial knowledge about the effectiveness of the field trip are available. No quantitative evidence for educational outcomes, or information about the way teachers prepare their students for the field trip is used.

Research questions addressed in the study are: (1) What is learned during the field trip? (2) What is the level of novelty for students during a field trip? (3) How does the novelty effect relate to the learning?

\section{Methodology}

\section{Respondents}

In September and October 2012, a total of 560 students from 27 classes participated in the excursion. Taking into account this limited timeframe and population size, the aim was to maximise the response rate by means of intense recruitment efforts. 484 students from 25 classes from 12 different schools ultimately participated in the study. This makes for a response rate of $86 \%$ (student level) and $93 \%$ (class level). Students were from grade 5 and 6 , most aged 10 or 11 years ( $49 \%$ and $44 \%$ respectively). The number of participating classes per school ranged from 1 to 6 . Table 1 summarises student characteristics. Out of the 25 classes, 24 teachers also took part in the research (19 women and 5 men).

Table 1. Respondents (students)

\begin{tabular}{lllllll}
\hline \multicolumn{5}{c}{ Numbers } & \multicolumn{5}{c}{ Percentages } \\
\hline Brade 5 & 128 & 96 & 224 & 45,5 & 45,9 & 46,3 \\
Grade 6 & 147 & 113 & 260 & 53,5 & 54,1 & 53,7 \\
\hline Total & 275 & 209 & 484 & 56,8 & 43,2 & 100 \\
\hline
\end{tabular}




\section{Design}

In May 2012 a pilot study took place, involving 93 students and 5 teachers. The pilot study involved 93 students filling out the questionnaires; 5 of them also participated in short interviews (about their understanding of the instructions and the items used). Teachers provided feedback on the instruction letters, time needed and any problems administrating the survey. As a result, some items in the questionnaires were modified, the layout of the survey was improved and some terminology was changed (e.g. the use of "field trip" instead of "excursion"). Based on teacher feedback, instruction letters were modified and completed.

A call for participation in the research took place in May 2012, followed by two reminders (telephone and email), aiming at a response rate that was as high as possible. Questionnaires for students and teachers were sent through the postal services, together with instruction sheets for both surveys. The field trips took place in the autumn, between 17 September and 15 October. Teachers provided time in the classroom for students to submit the self-administered surveys. Pre-test surveys were completed between 1 and 10 days before the field trip, and post-test surveys between 1 and 3 days after the field trip. There was an average of 4.5 days between the two surveys.

\section{Outcomes}

Environmental Values. In accordance with the field trip objectives set by the organiser, the study focussed on environmental values. Other affective goals were not taken into account. A wide range of instruments are available for the measurement of various different environmental values. In this study the "two major environmental values" (2MEV) model was used. This instrument, designed by Bogner and Wiseman (2006), measures ecological values on two orthogonal dimensions: preservation $(\mathrm{P})$ and utilisation $(\mathrm{U})$. This approach was chosen for a number of different reasons; most importantly, it is a widely used instrument and has several advantages compared to one-dimensional instruments for measuring values (Boeve-de Pauw \& Van Petegem, 2010). The common use of the instrument also allows for a good international comparison of results. On a regional scale, policymakers in Flanders are familiar with the $2 \mathrm{MEV}$. The $2 \mathrm{MEV}$ provides multiple benefits: it allows for comparisons between studies, it offers a fixed dimensional structure and it fits with current insight into the psychology of sustainable development (e.g. Johnson \& Manoli, 2010). The 2MEV has been shown to be valid and reliable in 20 countries (Schneller et al., 2015). Boeve-de Pauw (2011) translated the original instrument of Bogner and Wiseman (2006) into Dutch and confirmed the reliability of the translated instrument. This resulted in a 9-item scale for 
preservation $(\alpha=.75)$ and a 5-item scale for utilisation $(\alpha=.68)$ (Boeve-de Pauw, 2011). In the current study, construct validity was examined in an explorative factor analysis on post-data, followed by a reliability analysis, resulting in scales with $\alpha=.83$ and $\alpha=.69$ for preservation and utilisation. Sample items for the preservation dimension are "It upsets me to see the countryside taken over by building sites" and "We must set aside areas to protect endangered species", and for utilisation "Our planet has unlimited resources" and "Humans have the right to change nature as they see fit".

Inclusion of nature in the self. In this study, the inclusion of nature in the self (INS) scale was used (Schultz, 2001). This single-item instrument for measuring connectedness to nature limits the time required for the survey in the classroom, which is a practical advantage in conducting the study. The scale measures the extent to which individuals feel emotionally connected to the natural world, or the degree to which nature is integrated in their self-representation (Schultz, 2001). This consists of a series of seven pairs of differentially overlapping circles, labelled "self" and "nature". Students participating in the study were asked to mark the pair that represents their relation to nature to the greatest degree. An increase of connectedness to nature is considered a desirable effect of EE/ESD. INS has shown positive correlations with established instruments, e.g. NEP and CNS ( $r .20$ and .55, p <.01) (Mayer \& Frantz, 2004). Sellmann and Bogner (2013) find a positive correlation of INS with P and a negative correlation with U. Correlations of INS with $P$ and $U(r .65$ and $-.16, p<.01)$ found in this study are in line with these earlier findings.

Ecosystem Knowledge. Frick et al. (2004) distinguish three forms of environmental knowledge: action knowledge, impact knowledge and ecosystem knowledge. The cognitive goals of the heathland field trip are ecosystem-based. Existing instruments usually measure ecosystem knowledge on an abstract level. Therefore, a more specific questionnaire on the ecology of the specific heathland was developed, producing a set of 12 multiple choice questions (each with 1 correct answer out of 4). Only items with a positive correlation to the total score and with a correct answer-rate between $25 \%$ and $75 \%$ were used, resulting in a 10 -item scale for ecosystem knowledge. Sample items are "Which plant does not belong in the Kesselse Heide? (answers: nettle / oak / ling / sand sedge)" and "On the leaves of an oak you can sometimes see galls. What is inside them? (answers: nothing / a fruit / a seed / a larva)".

\section{Novelty}

Novelty was measured as a proxy. It was defined as inversely proportional to the product of 
two factors: earlier visits to the area and student preparation time in the classroom. For example, the novelty of the learning environment was high for students who were visiting the area for the first time and/or hadn't received any preparation in the classroom. Novelty was low for students who had a combination of (an) earlier visit(s) and more preparation time in the classroom.

(1) Students were asked "How often have you been in the Kesselse Heide in the last year, for example with the school, with your family or with the youth movement?" (answers: never / 1 time / 2 times / 3 times or more / I don't know)

(2) Teachers were asked "How much time did you spend preparing (the students) for the excursion?" (answers: (almost) none / less than 15 minutes / 15 min to 1/2 lesson / 1/2 to 1 lesson / 1 to 2 lessons / more than 2 lessons)

\section{Results}

\section{Educational outcomes - overall effects}

The study found no overall learning effects for the affective goals. No significant learning effects were found on INS, preservation and utilisation (Cohen's $d$ for all below .1). According to the literature, preserving and utilising natural resources should be balanced, rather than seen as competing forces, in order to reach SD. The field trips failed to increase preservation values and to change utilising values. However, participating in the field trip did lead to a large increase in ecosystem knowledge (Cohen's $d$ 1.55), thus realising an outcome considered to be desirable. Table 2 summarises the overall learning outcomes.

Table 2. Educational outcomes: overall effects. * marks significant differences

\begin{tabular}{lllllllll}
\hline & M pre & M post & M dif & SD & T & Df & $p$ & $\mathrm{~d}$ \\
\hline INS & 5,17 & 5,16 &,- 10 &, 83 &,- 18 & 419 &, 86 &, 01 \\
P & 22,12 & 21,96 &,- 16 & 2,16 & $-1,47$ & 397 &, 15 &, 07 \\
U & 9,24 & 9,28 &, 05 & 1,69 &, 55 & 394 &, 59 &, 02 \\
KNOW & 5,51 & 8,33 & 2,82 & 1,98 & 29,33 & 423 &, $00 *$ & 1,55 \\
\hline
\end{tabular}

\section{Educational outcomes - differentiated effects}

After pre-test scores showed variation between students for INS, P, U and KNOW, differentiated learning effects for different groups of students were measured. The sample 
was split into three percentile groups of equal size based on their pre-test scores for every variable. For each variable, separate analyses were run for students with low, average or high pre-test scores. Table 3 presents the main results. For KNOW, an overall large to very large positive effect from the field trip was found, regardless of the pre-test score. Environmental knowledge can contribute to the development of positive environmental behaviour. Students with a low pre-test score tended to gain more knowledge about the ecosystem than students with lower initial scores for KNOW. For INS, field trip participation has a small positive impact on students with a low pre-score on INS. However, no significant effects were found for students with medium or high INS pre-scores. On preservation values, a small positive effect was found for students with an initial low score while small negative effects were found for other students. Concerning utilisation values, a medium and negative effect was found for the subgroup with the highest pre-test scores. The effect of field trip participation was small and positive for the students with the lowest pre-test scores. No significant effect on utilisation was found for the middle group. Although part of the differences could be explained by ceiling effects, the results suggest that the field trip is not effective for all students.

Table 3. Differentiated educational outcomes. ${ }^{*}$ marks significant differences

\begin{tabular}{llllllllll}
\hline & Start & M pre & $\mathbf{M}$ & M dif & SD & T & Df & p & d \\
& & \multicolumn{7}{c}{ post } \\
\hline INS & Low & 3,63 & 3,92 & 0,30 & 0,88 & 3,86 & 130 &, 000 &, $37^{*}$ \\
& Medium & 5,00 & 5,10 & 0,10 & 0,74 & 1,39 & 113 &, 167 &, 27 \\
& High & 6,44 & 6,14 & 0,12 & 0,74 & 1,40 & 174 &, 158 &, 26 \\
\hline P & Low & 18,68 & 19,29 & 0,61 & 2,55 & 2,66 & 123 &, 009 &, $29^{*}$ \\
& Medium & 22,16 & 21,81 & $-0,34$ & 1,97 & $-2,02$ & 134 &, 046 &,$- 19^{*}$ \\
& High & 25,14 & 24,47 & $-0,67$ & 1,74 & $-4,53$ & 138 &, 000 &, $33^{*}$ \\
\hline U & Low & 6,71 & 7,47 & 0,31 & 1,79 & 2,02 & 134 & 0,012 &, $32^{*}$ \\
& Medium & 9,32 & 9,36 & 0,04 & 1,49 & 0,35 & 132 &, 728 &, 04 \\
& High & 11,84 & 11,12 & $-0,71$ & 1,40 & $-5,62$ & 126 &, 000 &,$- 51^{*}$ \\
\hline KNOW & Low & 3,26 & 7,65 & 4,40 & 1,82 & 27,77 & 132 &, 000 & $3,25^{*}$ \\
& Medium & 5,48 & 8,23 & 2,74 & 1,48 & 23,44 & 159 &, 000 & $2,78^{*}$ \\
& High & 7,83 & 9,15 & 1,31 & 1,37 & 10,97 & 130 &, 000 & $1,12^{*}$ \\
\hline
\end{tabular}

To summarise, the study shows that participating in the field trip has differentiated effects on students, dependent on their initial pre-test scores. Participating in the field trip was also found to reduce initial differences between (groups of) students. This applies to the 
different educational outcomes: INS, P, U and KNOW. In short, low starters gain more by participating in the field trip than their peers who have higher initial scores

\section{How novel?}

Considering the students' visits to the particular area of the field trip, results show that for 190 students the field trip was their first visit to the area (45\%). 99 students remembered one earlier visit in the past year, 38 students remembered 2 visits and 67 of them remembered 3 or more ( $24 \%, 9 \%$ and $16 \%$ respectively). 26 students didn't know or couldn't remember if they had ever visited the area before (6\%).

With regard to student preparation, the results show that teachers vary in the amount of time they spend preparing their students for the field trip. A large group of teachers spent (almost) no time doing this. 10 teachers said they spent (almost) no time preparing their students for the field trip. 7 said they spent less than 15 minutes, 15 minutes to $1 / 2$ lesson or more than $1 / 2$ lesson to 1 lesson on student preparation before the field trip $(4,2$ and 1 teacher respectively). 4 teachers reported preparation times of between 1 and 2 lessons and 3 teachers said they spent more than 2 lessons orientating their students.

Combining both factors, and taking into account that students are grouped in classes, we can see that 94 students have never been on the Kesselse Heide before and have received (almost) no preparation in the classroom ( $22 \%$ of the students). For this group, the novelty of the learning environment is considered high (see Table 4, marked with *). On the other hand, 61 students combine at least one recent visit with half an hour or more preparation in the classroom, resulting in much lower novelty levels (15\% of the students) (see Table 4 , marked with \#). Other students combine earlier visits and preparation in ways that are thought to result in moderate novelty levels (63\% of the students).

\section{Novelty effect}

To find out whether there was a novelty effect on cognitive and affective learning outcomes, regression analyses were run, looking for linear as well as curvilinear (quadratic) impacts of novelty on increases in the learning outcomes. Results are displayed in Table 5. No significant effects from novelty on INS, $\mathrm{P}$ and $\mathrm{U}$ were found. This is not surprising considering the overall limited learning effects for these variables. On the other hand, a significant positive effect from 
novelty on KNOW was found.

Table 4. How novel is the learning environment?

\begin{tabular}{lllllll}
\hline visits / preparation & 0 & 1 & 2 & $3+$ & $?$ & Total \\
\hline None & $94^{*}$ & 44 & 16 & 18 & 0 & 172 \\
Less than 15 minutes & 27 & 22 & 3 & 9 & 0 & 61 \\
15 min to $1 / 2$ lesson & 5 & 20 & 5 & 6 & 4 & 40 \\
$1 / 2$ to 1 lesson & 0 & $2 \#$ & $5 \#$ & $12 \#$ & 4 & 23 \\
1 to 2 lessons & 25 & $9 \#$ & $7 \#$ & $15 \#$ & 15 & 71 \\
More than 2 lessons & 39 & $2 \#$ & $2 \#$ & $7 \#$ & 3 & 53 \\
\hline Total & 190 & 99 & 38 & 67 & 26 & 420 \\
\hline
\end{tabular}

* higher novelty levels \# lower novelty levels

Table 5. The novelty effect (linear and non-linear).

\begin{tabular}{llll}
\hline Outcome & Expl. var. & $\beta$ & $\mathrm{P}$ \\
\hline INS & Intercept &, 00 &, 963 \\
& Novelty &, 24 &, 396 \\
& Novelty &,- 23 &, 420 \\
\hline $\mathrm{P}$ & Intercept &, 00 &, 980 \\
& Novelty &, 32 &, 210 \\
& Novelty &,- 29 &, 255 \\
\hline U & Intercept &,- 02 &, 673 \\
& Novelty &, 08 &, 740 \\
& Novelty &,- 06 &, 822 \\
\hline KNOW & Intercept &, 00 &, 860 \\
& Novelty &, $29 *$ &, 000 \\
& Novelty &,$- 17 *$ &, 028 \\
\hline
\end{tabular}

With regard to knowledge, both the linear and the quadratic model are significant. Values for novelty $\mathrm{x}$ novelty were negative, which confirms the curvilinear relation between novelty and learning. These findings are in line with theories on the effect of novelty, as described in the theoretical framework of this article, indicating that while a little novelty on the field trip environment increases learning, too much novelty will have the opposite effect. 


\section{Discussion and conclusions}

\section{Discussion}

EE school field trips are common practice in schools in Flanders, representing important and unique opportunities to empower students to make choices regarding their environmental and sustainability behaviour. In Flanders, field trips are among the most applied practices used to address cross curricular goals in formal education. Their effectiveness is therefore of high importance. The goal of the current study was to explore whether the level of novelty students experience impacts what is learned during a trip in nature, and whether the novelty of the learning environment relates to the learning outcomes. We also explored the usefulness of the novelty framework in order to understand the importance of field trip preparation.

The study shows that participating in the excursion resulted in significant learning effects. This is in line with literature about the effectiveness of field trips (Dewitt \& Storksdieck, 2008), even when they are short (Sellman \& Bogner, 2013). However, results suggest that the field trip mainly affected student ecosystem knowledge. Research supports the idea that developing environmental knowledge, inclusion of nature in the self and environmental values are three key goals for contemporary EE and ESD. The overall effects found on inclusion of nature in the self, preservation values and utilisation values are small and insignificant. The field trip succeeds in achieving affective goals only for some students. Literature shows that field trips can be a good way of achieving affective goals (e.g. Storksdieck, 2006), however, the field trip examined in this work was not successful in doing so. It should be stressed that the current study does not consider why cognitive goals are achieved better than affective goals. While focussing on the impact of novelty, the pedagogy of the trip itself was not examined but approached as a black box. Research states that the development of environmental knowledge, inclusion of nature in the self and environmental values in combination are important goals for EE and ESD in promoting ecological behaviour (Roczen et al., 2014). The field trip studied succeeds in reinforcing one in three of these factors (environmental knowledge: only ecosystem knowledge was measured), but it doesn't show its effectiveness in reaching the affective goals the organisation has set.

To gain more insight on differentiated learning effects, the sample was split into three equally large subgroups based on their pre-test scores for different learning outcomes. Results indicate that educational outcomes differ for different subgroups of students. Participating in the field trip increases preservation values and inclusion of nature in the self for students with an initial low score, the "low starters". Participating in the field trip also decreases utilisation values of "high starters" and adversely, it increases utilisation values of "low starters". The 
learning outcomes of the field trip are thus dependent on the group of students studied: low starters gain more by participating in the field trip than their peers who have higher initial scores. Again, further research is required to explain and refine these findings, resulting in more insight into the standardised educational approach of the field trip. This "one size fits all" approach could be less effective, while a differentiated approach would fit more students.

Novelty was measured using a simple-to-use proxy, the product of earlier visits to the area and student preparation time in the classroom. Considering the first factor, results show that for a high proportion of students $(45 \%)$, the field trip is their first visit to the area. With regard to student preparation, teachers differ in the amount of time they spend preparing their students for the field trip. In general, the time spent on novelty-reducing preparation is limited. Of 24 teachers, 10 said they spent (almost) no time preparing their students for the field trip. These results are in line with earlier findings about limited time spent preparing students for a field trip (Kisiel, 2005; De Witt \& Storksdieck, 2008).

Combining both factors influencing novelty, results show that $22 \%$ of the students had never been to the Kesselse Heide before and had received (almost) no preparation in the classroom. Literature suggests that students that are unfamiliar with the setting will spend most of the time acquainting themselves, rather than concentrating on other learning. According to literature about novelty, for these groups, the novelty of the setting is plausibly (too) high, which could hinder learning. On the other hand, 15\% of the students combined at least one recent visit they remember with at least half a lesson preparation time in the classroom. This combination results in lower novelty levels. The results show that in between this are $63 \%$ of the students; these students experience moderate novelty levels in comparison to the other students. It should be noted that the heathland is a relatively novel setting for learning for all the students, compared to the classroom.

Another question this study wanted to explore was how novelty relates to the learning of the students on the field trip, and whether novelty is a useful framework by which to understand field trip preparation. To do so, regression analyses were run, looking for linear and curvilinear (quadratic) impacts of novelty on learning outcomes. Although the operationalisation has limitations, results suggest the existence of a significant novelty effect for environmental knowledge. The curvilinear relationship found between novelty and knowledge gain indicates that a little novelty promotes learning, while too much novelty will have the opposite effect. Consequently, the students for whom the Kesselse Heide was "too" novel did not learn as much as those at the optimum level of novelty. This is in line with earlier findings (e.g. Balling \& Falk, 1980). The results from this study provide evidence for the 
theoretical framework of novelty, as applied to a typical practice in EE and ESD in Flanders schools.

\section{Recommendations}

Based on the results, we can put forward recommendations for EE/ESD practice in Flanders. First, for practitioners like the nature centre staff members guiding and organising this field trips, a stronger focus on affective goals seems to be worth considering. By focusing on these goals, the field trips could improve the promotion of environmental values and connectedness, both important antecedents of the desired environmental behaviour. Second, students differ from each other in their environmental knowledge, values and connectedness to nature prior to the field trip. More tailor-made field trips could build on these differences, creating a greater impact than the current "one size fits all" approach. The use of quick pre-tests (e.g. INS) may be considered for identifying relevant student characteristics.

Third, encouraging and facilitating teacher preparation seems a valuable focus for future practice. Existing models can help with developing an approach in which preparing the students is an essential part of the field trip. The implementation of pre-visit activities in the classroom could be promoted. Nature centres and others of their kind offering EE/ESD activities and resources could help teachers $a$ in doing so. A wide range of good practices already exist to support teachers in different phases of the field trip (e.g. Connolly et al., 2006), making implementation a feasible challenge. Finally, the understanding of "novelty" could be promoted to improve field trip practice. As stated above, in the current study novelty was measured as a proxy and three dimensions of novelty were explored (geographical, psychological and cognitive), however, these dimensions were not included in this article. Further development and operationalisation is required to create a valid and practical tool to measure novelty. The results do however present evidence for the impact of novelty on learning and are thus a starting point for further research into this important and under researched issue.

\section{Limitations of the study}

Despite the findings, some important limitations of the study need to be acknowledged. As noted above, the concept of novelty was measured using a proxy, combining the number of earlier visits and classroom time spent on preparation. This operationalisation does not take into account the nature and quality of the preparation and this aspect requires further development and validation. Second, for reasons of practical feasibility, the pre-post design was limited in time, with an average of 4 or 5 days between the two surveys. This 
characteristic creates a risk of testing bias and it does not allow us to identify long term effects. A design including a retention test and a longer follow up period would be worthwhile. This was not achievable within the context of this research. Third, the research model could be extended, integrating a post-field trip phase in the classroom and including more contextual factors. Finally, the study was based on data collected before and after the field trip, with the trip treated as a black box. This approach has important limitations, including not taking into account what happens during the field trip. Further research including field trip pedagogy could provide more insight into what impacts learning effects of the field trip.

\section{Conclusion}

EE field trips are common practice in Flanders and the Benelux, and they are an important part of EE in schools. Research on the effectiveness of these field trips is still scarce, despite the importance and the increasing pressure on field trip practice. This study adds to the existing knowledge base, applied to a regional situation. Our results are in line with findings that suggest that short field trips often fail to meaningfully impact on students (e.g.), and therefore raise the question of how to deal with this issue. One way of increasing the impact of field trip is through attuned preparation in before the field trip takes place. The novelty framework offers a practical starting point for looking at and improving local EE and ESD field trip practices, and our current results offer some of the first empirical support for the impact of novelty on learning. More research on novelty and effectiveness of school field trips is needed across different EE excursions and with a larger number of teachers. Such research could focus on different preparation practices and the operationalisation of an instrument measuring different dimensions of novelty. Also, research into the long term effects of school field trips in Flanders and research integrating the field trip pedagogy and the pre- as well as the post-field trip phase would be valuable additions to the existing knowledge base.

\section{References}

Ajzen, I. (1991). The theory of planned behavior. Organizational Behavior and Human Decision Processes, 50, 179-211.

Anderson, D. \& Lucas, K. B. (1997). The effectiveness of orienting students to the physical features of a science museum prior to visitation. Research in Science Education, 27(4), 485495.

Anderson, D. \& Zhang, Z. (2003). Teacher perceptions of field trip planning and implementation. Visitor Studies Today, 6(3), 6-12. 
Balling, J. D. \& Falk, J. H. (1980). A perspective on field trips: environmental effects on learning. Curator: The Museum Journal, 23, 229-240.

Behrendt, M. \& Franklin, T. (2014). A review of research on school field trips and their value in education. International Journal of Environmental \& Science Education, 2014(9), 235-245.

Bitgood, S. (1989). School field trips: an overview. Visitor Behavior, IV(2), 3-6.

Boeve-de Pauw, J. (2011). Valuing the invaluable: effects of individual, school and cultural factors on the environmental values of children. Antwerpen-Apeldoorn: Garant.

Boeve-de Pauw, J. \& Van Petegem, P. (2010). Evaluating the impact of environmental education: the NEP vs the 2-MEV as an outcome measure. Proceedings of the 14th IOSTE Symposium. Presented at the 14th international symposium of the International Organisation of Science and Technology Education (IOSTE), Bled, Slovenia.

Boeve-de Pauw, J. \& Van Petegem, P. (2011). The effect of Flemish eco-schools on student environmental knowledge, attitudes, and affect. International Journal of Science Education, 33(11), 1513-1538.

Boeve-de Pauw, J. \& Van Petegem, P. (2013). A cross-cultural study of environmental values and their effect on the environmental behavior of children. Environment \& Behavior, 45(5), 551-583.

Bogner, F. X. (1998). The influence of short term outdoor ecology education on long-term variables of environmental perspective. Journal of Environmental Education, 29(4), 17-29.

Bogner, F. X. \& Wiseman, M. (2006). Adolescents' attitudes towards nature and environment: quantifying the 2-MEV model. The Environmentalist, 26, 247-254. Connolly, R., Groome, M., Sheppard, K. \& Stroud, N. (2006). Tips from the field: advice from museum experts on making the most of field trips. The Science Teacher 73, 42-45.

Cotton, D. R. E. (2009). Field biology experiences of undergraduate students: the impact of novelty space. Journal of Biological Education, 43(4), 169-174.

DeWitt, J. \& Osborne, J. (2007). Supporting teachers on science-focused school trips: towards an integrated framework or theory and practice. International Journal of Science Education, $29(6), 685-710$.

DeWitt, J. \& Storksdieck, M. (2008). A short review of school field trips: key findings from the past and implications for the future. Visitor Studies, 11(2), 181-197.

Dillon, J., Rickinson, M., Teamey, K., Morris, M., Choi, M. Y. \& Sanders, D. (2006). The value of outdoor learning: evidence from research in the UK and elsewhere. School Science Review, $87(320)$. 
Elkins, J. T. \& Elkins, N. M. L. (2007). Teaching geology in the field: significant geoscience concept gains in entirely field-based introductory geology courses. Journal of Geoscience Education, 55(2), 126-132.

Falk, J. H. (1983). Field trips: a look at environmental effects on learning. Journal of Biological Education, 17(2), 137-141.

Frick, J., Kaiser, F. \& Wilson, M. (2004). Environmental knowledge and conservation behavior: exploring prevalence and structure in a representative sample. Personality and Individual Differences, 37(8), 1597-1613.

Griffin, J. \& Symington, D. (1997). Moving from task-oriented to learning-oriented strategies on school excursions to museums. Science Education, 81, 763-779.

Hofstein, A. \& Rosenfeld, S. (1996). Bridging the gap between formal and informal science learning. Studies in Science Education, 28, 87-112.

Johnson, B. \& Manoli, C. C. (2010). The $2 \mathrm{MEV}$ scale in the United States: a measure of children's environmental attitudes based on the theory of ecological attitude. The Journal of Environmental Education, 42 (2), 84-97.

Kaiser, F. G., Roczen N., \& Bogner, F. X. (2008). Competence formation in environmental education: advancing ecology-specific rather than general abilities. Umweltpsychologie, $12(2), 56-70$.

Kisiel, J. (2005). Understanding elementary teacher motivations for science field-trips. Science Education, 89, 936-955.

Kisiel, J. (2006). More than lions and tigers and bears. Creating meaningful field trip lessons. Science Activities, 43(2), 7-10.

Kollmuss, A. \& Agyeman, J. (2002). Mind the gap: why do people act environmentally and what are the barriers to pro-environmental behavior? Environmental Education Research, 8(3), 239-260.

Liefländer, A. K., Fröhlich, G., Bogner, F. X. \& Schultz, P. W. (2013). Promoting connectedness with nature through environmental education. Environmental Education Research, 19(3), 370-384.

Mayer, F. S. \& Frantz, C. M. (2004). The connectedness to nature scale: a measure of individuals' feeling in community with nature. Journal of Environmental Psychology, 24 (2004), 503-515.

Meiers, N. J. (2010). Designing effective field trips at zoos and aquariums - a literature review. Middlebury College, Middlebury, Vermont.

Michie, M. (1998). Factors influencing secondary science teachers to organise and conduct field trips. Australian Science Teacher's Journal, 44, 43-50. 
Milfont T. L., Duckitt J. (2004). The structure of environmental attitudes: A first- and secondorder confirmatory factor analysis. Journal of Environmental Psychology, 24, 289-303.

Milfont T. L., Duckitt J., Cameron L. D. (2006). A cross-cultural study of environmental motives concerns and their implication for environmental behavior. Environment and Behavior, 38, 745-767.

Morag, O. \& Tal, T. (2011). Assessing learning in the outdoors with the Field Trip in Natural Environments (FiNE) framework. International Journal of Science Education, 2011, 1-33.

Orion, N. (1993). A model for the development and implementation of field trips as an integral part of the science curriculum. School Science and Mathematics, 93, 325-331.

Orion, N. \& Hofstein, A. (1994). Factors that influence learning during a scientific field trip in a natural environment. Journal of Research in Science Teaching, 31, 1097-1119.

Otto, S., \& Penisini, P. (2017). Nature-based environmental education of children: Environmental knowledge and connectedness to nature, together, are related to ecological behaviour. Global Environmental Change, 47, 88-94.

Provincie Antwerpen (n.d.). Dwars door de heide. Retrieved from http://www.provant.be/vrije_tijd/domeinen/kesselse_heide/educatie/met_de_klas/

Rickinson, M., Dillon, J., Teamey, K., Morris, M., Choi, M. Y., Sanders, D. \& Benefield, P. (2004) A review of research on outdoor learning. Preston Montford, Shropshire: Field Studies Council.

Roczen, N., Kaiser, F., Bogner, F. \& Wilson, M. (2014). A competence model for environmental education. Environment and Behavior, 46(8), 972-992.

Rokeach, M. (1968). Beliefs, attitudes, and values: A theory of organization and change. San Francisco: Jossey-Bass.

Schneller, A. J., Johnson, B. \& Bogner, F. X. (2015). Measuring children's environmental attitudes and values in northwest Mexico: validating a modified version of measures to test the Model of Ecological Values (2-MEV). Environmental Education Research, 21(1), 61-75.

Schultz, P. W. (2001). The structure of environmental concern: concern for self, other people, and the biosphere. Journal of Environmental Psychology, 21, 327-339.

Schultz, P. W. (2002). Inclusion with nature: The psychology of human-nature relations. In P. Schmuck \& P. W. Schultz (Eds.), Psychology of sustainable development. Dordrecht: Kluwer Academic Publishers.

Sellmann, D. \& Bogner, F. X. (2013). Effects of a 1-day environmental education intervention on environmental attitudes and connectedness with nature. European Journal of Psychology of Education, 28, 1077-1086. 
Sleurs, W., De Smet, V. \& Gaeremynck, V. (2008). Duurzame ontwikkeling. Hoe integreren in onderwijs?. Antwerpen: Uitgeverij De Boeck.

Stern, P. (2000). Toward a coherent theory of environmentally significant behavior. Journal of Social Issues, 56(3), 407-424.

Storksdieck, M. (2006). Field trips in environmental education. Berliner Wissenschafts-Verlag, Berlin, Germany.

Tal, R. T. \& Morag, O. (2009). Reflective practice as a means for preparing to teach outdoors in an ecological garden. Journal of Science Teacher Education, 20(3), 245-262.

United Nations (2005). Education for sustainable development (ESD). Retrieved from http://www. unesco.org/ new/en/education/themes/leading-the-international-

Van Poeck, K. \& Loones, J. (2010). De vlag en de lading. Educatie voor duurzame ontwikkeling. Brussel: Departement Leefmilieu, Natuur en Energie.

Wiseman, M. \& Bogner, F. X. (2003). A higher-order model of ecological values and its relationship to personality. Personality and Individual Differences, 34, 783-794. 